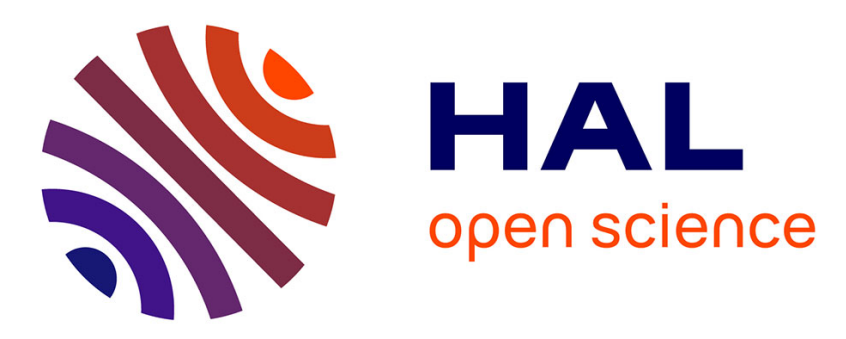

\title{
Effects of abrasive tools on surface finishing under brittle-ductile grinding regimes when manufacturing glass
}

Ibrahim Demirci, Sabeur Mezghani, Ali Mkaddem, Mohamed El Mansori

\section{- To cite this version:}

Ibrahim Demirci, Sabeur Mezghani, Ali Mkaddem, Mohamed El Mansori. Effects of abrasive tools on surface finishing under brittle-ductile grinding regimes when manufacturing glass. Effects of abrasive tools on surface finishing under brittle-ductile grinding regimes when manufacturing glass, 2010, 210, pp.466-473. 10.1016/j.jmatprotec.2009.10.009 . hal-00881006

\section{HAL Id: hal-00881006 https://hal.science/hal-00881006}

Submitted on 27 Nov 2013

HAL is a multi-disciplinary open access archive for the deposit and dissemination of scientific research documents, whether they are published or not. The documents may come from teaching and research institutions in France or abroad, or from public or private research centers.
L'archive ouverte pluridisciplinaire HAL, est destinée au dépôt et à la diffusion de documents scientifiques de niveau recherche, publiés ou non, émanant des établissements d'enseignement et de recherche français ou étrangers, des laboratoires publics ou privés. 


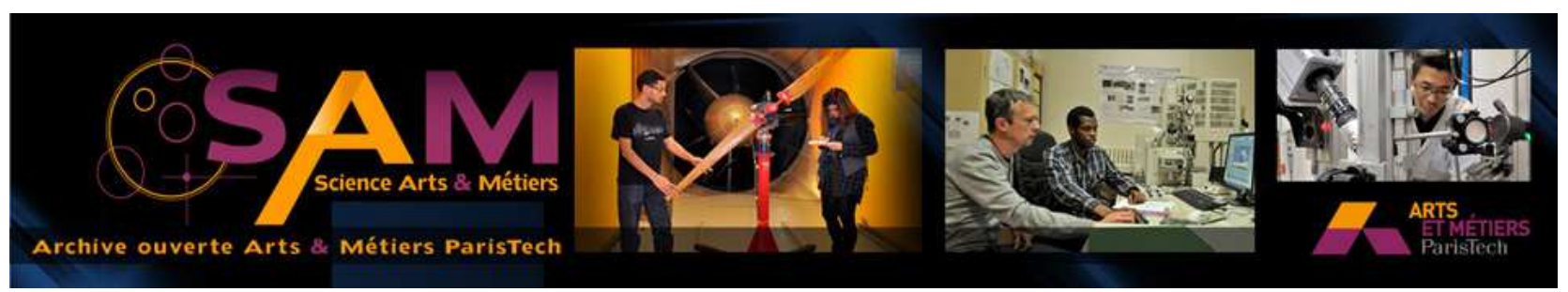

\section{Science Arts \& Métiers (SAM)}

is an open access repository that collects the work of Arts et Métiers ParisTech researchers and makes it freely available over the web where possible.

This is an author-deposited version published in: http://sam.ensam.eu

Handle ID: .http://hdl.handle.net/10985/7475

\section{To cite this version :}

Ibrahim DEMIRCI, Sabeur MEZGHANI, Ali MKADDEM, Mohamed EL MANSORI - Effects of abrasive tools on surface finishing under brittle-ductile grinding regimes when manufacturing glass - Journal of Materials Processing Technology - Vol. 210, p.466-473 - 2010 


\title{
Effects of abrasive tools on surface finishing under brittle-ductile grinding regimes when manufacturing glass
}

\author{
I. Demirci*, S. Mezghani, A. Mkaddem, M. El Mansori
}

Arts et Métiers Parts Tech, LMPF, Rae Saint Domatanue, BP508, 51006 chähons-en-Champagne, France

\begin{abstract}
A B S T R A C T
This paper addresses the effects of bonds and grains of abrasive tools on the edge aspect of ground glass surface. Diamond grains and silicon carbide (SiC) grains combined with two bond types, i.e., resin and metal, were considered for this study. The surface edge characteristics were characterized using scanning electron microscope (SEM) and interferometer observations. In particular, the spectrum of arithmetic mean was investigated for distinguishing the different scales of analysis. Experimental results showed that the grinding forces vary sensitively with bond type and wheel velocity. Using diamond grains' wheel, However, using a resin-bonded wheel, two mechanisms of material removal were revealed according to grains' type, (i) A partial ductile regime, i.e., ductile streaks and brittle fracture, obtained with diamond grains, and (ii) a fully ductile regime obtained with SiC grains. Thus, it was found that ground surface obtained using SiC grains' wheel has a better roughness than that obtained using diamond grains wheel. Besides, SiC grains seem to lead to more marked streaks and form defects.
\end{abstract}

Keywords:

Class grinding

Abrasive wheets

Mutti-scale analysis

Surface damage

\section{Introduction}

Nowadays, abrasion removal process in manufacturing brittle materials is still badly known. For example, the interaction between the abrasive multi-grains and the job surface in grinding is a complex process. The process is complicated, in one hand, by the random nature of the abrasive grains in their shape and geometrical arrangement and, in other hand, by the nature of the material, i.e., brittle material.

For several years, many investigations (Fielden and Rubenstein, 1969; Vaidyanathan and Finnie, 1972: Mairlot, 1972) underlined the possibility of material flow under certain conditions when grinding glass. Bowden and Hughes (1937) and Bowden and Scott (1958) found that material flow occurs when the temperature at surface reaches the softening threshold of the glasses. In addition, Bridgman and Simon (1953) showed that glasses might flow even at room temperature when high hydrostatic stresses were applied. The glass behavior was further understood through the analysis of damage of surface finish. Generally, brittle fracture at surface generates severe sub-surface damage and poor surface finish as reported by Sun et al. (2006). However, under good conditions, better surface finish with ductile streaks can be obtained on brittle materials (Zhong, 2003). It was reported in a previous work

\footnotetext{
+ Corresponding author.

E-matl address: ibrahim demircielensam.fr (I. Demirci).
}

(Demirci et al., 2008) that damage varied sensitively with processing parameters, i.e., wheel velocities, feed rate and depth of cut. It might occur under three different regimes, (i) At relatively low velocities, a first partial ductile regime in which cutting action was accompanied by chip formation takes place generally.(ii) Fragmentation regime, however, takes place at intermediate velocity values, and finally, (iii) a second partial ductile regime, characterized by ploughing action with displaced material, can also be reached for relatively high velocities. It is worth to note that these findings were obtained for a single type of wheel. The characteristics of processed surface should markedly evolve with the nature of grains and bond of the wheel.

Generally, the bond plays a very important role, as it is responsible for retaining the rigid inclusions against pull-out mechanisms (Malkin, 1989). Surface finish performances and the obtained flow are linked with nature (Desmars and Margerand, 1994) and, of course, with the wear of bond (Venkatesh et al., 2005). In grinding, many differences in surface characteristics were underlined between the resin bond and the metallic bond. Resin is a soft bond that offers better quality of surface finish. For similar diamond grits' size, surface roughness produced by a bronze-bonded tool is higher than the one produced by resin-bonded tool. However, wear of resin-bonded stones generally appears faster. This can decrease efficiency of the wheel as mentioned by Tong et al. (2006). It was found that ductile streaks at ground surface are found more when resin bond is used than when metal bond is used (Venkatesh et al. 2005: Desmars and Margerand, 1994). 
Density, repartition, shape, nature and wear type of grains influence the grinding variables and quality of surface finish. Huerta (1974) investigated the evolution of force components and specific energy under different working parameters, He showed that it is easier to obtain viscous flow with silicon carbide grains than with diamond grains, Further, he evoked that grinding energy produced is more important using SiC grits' stone rather than using diamond one. Moreover, during grinding, grains' damage should affect the surface state. The quality of ground surface, i.e, roughness, was correlated with the wear of abrasive grains. In this context, Luo et al, (2006) investigated the characteristics and the wear modes of the diamond grits in the cut-off grinding glass using thin wheel. From their experimental findings, they showed that the major wear process of diamond particles observed for lower velocity follows three consecutive mechanisms: (i) protrusive, (ii) partial breakage, and (iii) pulled-out. These mechanisms result in a freer cutting ability, a better grinding ratio, and a better straightness of cut. However, using alumina abrasive grains, Belkhir et al, (2007) found changes in the characteristics of the grains are due to the edge rounding caused by wear and changes in the edge angles are caused by fracture In their work, Takahashi and Funkenbusch $(2000)$ checked bronze-bonded wheel composed of diamond grains for three glass types with distinct grinding behavior. They showed that the specific energy of processing increases rapidly with abrasive grains' dam age and declines the strong dependency of grinding performance on both the process conditions and the glass type.

In this study, the influence of tool's structure is investigated. Indeed, the glass ground joints for two types of bonds and two types of grains were investigated under different working conditions. In particular, microscopic observations and multi-scale analysis were used to characterize the surface finish and to identify the different abrasion regimes.

\section{Experimental procedure}

\subsection{Grinding devices: tools' properties and process variables}

All the grinding experiments of glass were performed on CNC Computer Numerically Controlled) machine (VEC500 MIKRON). A dynamometric cell (Kistler device), relied to the acquisition system and fixed under the glass specimen that was supplied in rectangular box shape of size $400 \mathrm{~mm} \times 100 \mathrm{~mm} \times 10 \mathrm{~mm}$, was used for recording the normal $\left(F_{n}\right)$ and tangential $\left(F_{t}\right)$ force components, The grinding operation has been carried out on only one edge of the specimen. Fig. 1a shows a schematic illustration of the whee and specimen configuration. A power cell is also available to record the active power during the grinding operation. The machine is equipped with a tank and a pump to inject the cutting liquid in the grinding zone.

A specified system installed on the tools ensures a sustainex cooling. This system follows the path of grinding. The fluid used is water whose speed is similar to that of wheels. The working parameters during the grinding of glass are as follows: wheel velocity $\left(v_{s}\right)$ workpiece velocity $\left(v_{w}\right)$ and the depth of cut $\left(a_{p}\right)$ as illustrated in Fig. 1a. The analysis will be limited to soda-lime-silica glass (float glass).

In this study, the influence of the wheel tool structure (type of grains and material of bond) on grinding mechanisms, material removal, and surface finish was investigated. Three differen wheel types with $100 \mathrm{~mm}$ diameter were considered: (i) diamond wheel with metal bond (diamond-M) and regular grains with plane faces, (ii) diamond wheel with resin bond (diamond-R) and irreg ular grains with acute angle, and (iii) silicon carbide wheel with resin bond (SiC-R) and irregular grains with acute angle. Fig. 1b-c shows examples of shape of diamond and silicon carbide grains.
The grains of the wheel used here have similar morphology than those shown in Fig. 1 whereas they have smaller size. These wheels with R grade were supplied by Asahi Diamond Industrial Europe SAS. The grit size of diamond and $\mathrm{SiC}$ is $46 \mu \mathrm{m}$, which corresponds to FEPA 46. The concentration of grain in each wheel was 3100 par. ticles per $\mathrm{mm}^{3}$. Moreover, resin-bonded diamonds were coated by a fine layer of nickel. The thickness of the grinding wheel is $10 \mathrm{~mm}$. All characteristics of these three wheel tools are listed in Table 1.

Each of the wheels was initially dressed using single-point diamond tool. Before starting the acquisition of data, wheels were tested and "runned-in" on glass samples, During the experiments, semi-finished configuration has been used. The manufacturer used wheel velocities ranging between 15 and $35 \mathrm{~ms}^{-1}$, workpiece velocities between 1 and $5 \mathrm{mmin}^{-1}$ and maximum depth of cut of $0.5 \mathrm{~mm}$. However, this depth must be larger than the grains' diameter. The wheels were not re-trued and re-dressed after each test whereas they were re-trued and re-dressed by the vendor after each series of tests. However, in this study, the focus is not on the investigation of the wear mechanisms but on the glass surface.

Nine velocities were used for diamond-M wheel. Six velocities were used for diamond-R and SiC-R. The CNC machine is limited to $2.5 \mathrm{~m} \mathrm{~min}^{-1}$. The depth of cut must be lower than $0.5 \mathrm{~mm}$ but larger than the grain's diameter. In addition, Huerta (1974) showed that in general, the increase in the depth of cut $\left(a_{p}\right)$ by a factor six does not produce noticeable differences in resulting surface morphology when grinding with diamond wheel. For these reasons, only one value of depth of cut was used, i.e., $0.1 \mathrm{~mm}$ of material was removed from the glass test-piece for each wheel. All the parameters values are listed in Table 2. Each test was repeated 5 times.

\subsection{Multi-scale surface analysis}

The conventional approach leading to a simple value of arithmetic roughness $\left(R_{a}\right)$ in a limited band of wavelength is not enough for characterizing precisely the surface finish of the glass edge acquired after grinding. This is because the topography of the surface is changed on a broad band of wavelength. A wavelet-based method using Mexican hat wavelet is developed to analyze the multi-scale feature of the finished ground glass surfaces' texture (Fielden and Rubenstein, 1969). This multi-scale surface analysis method was summarized here. An extensive description of this approach is available in open literature (Lee et al., 1998).

The methodology consists of the decomposition of the surface data sets into different components at each scale from roughness to waviness (Zahouani et al., 2001). This decomposition uses continuous wavelet transform which can be viewed as a mathematical microscope, where the resolutions are the basic functions obtained from a single wavelet or mother wavelet $\Psi(x, y)$ by dilation (or compression) and translation (Zahouani et al, 2008). The surface topography components pass through a filter bank composed of a set of contracting wavelets. The 2D wavelet transform of a 2D surface topography $f(x, y)$ can be defined as follows:

$W_{b, a}(x, y)-\frac{1}{\sqrt{a_{x} a_{y}}} \int_{-\infty}^{+\infty} f(x, y) \psi\left(\frac{x-b_{x}}{a_{x}}, \frac{y-b_{y}}{a_{y}}\right) d x d y$

where $a_{x}$ and $a_{y}$ are the contraction coefficients with respect to the $x$-axis and $y$-axis, respectively. $b_{x}$ and $b_{y}$ are the translation coefficients with respect to $x$-axis and $y$-axis, respectively. It is worth to note that the term $1 / \sqrt{a_{x} a_{y}}$ is required to conserve energy across scales for the two-dimensional wavelets.

The surface topography is analyzed at various locations by Mexican hat wavelets of various dilatations. The two-dimensional Mexican hat wavelet specified on $(x, y)$ coordinate system is given by the following form:

$\Psi(\boldsymbol{r})-\left(2-|\boldsymbol{r}|^{2}\right) e^{-|\boldsymbol{r}|^{2} / 2}$ 
(e)
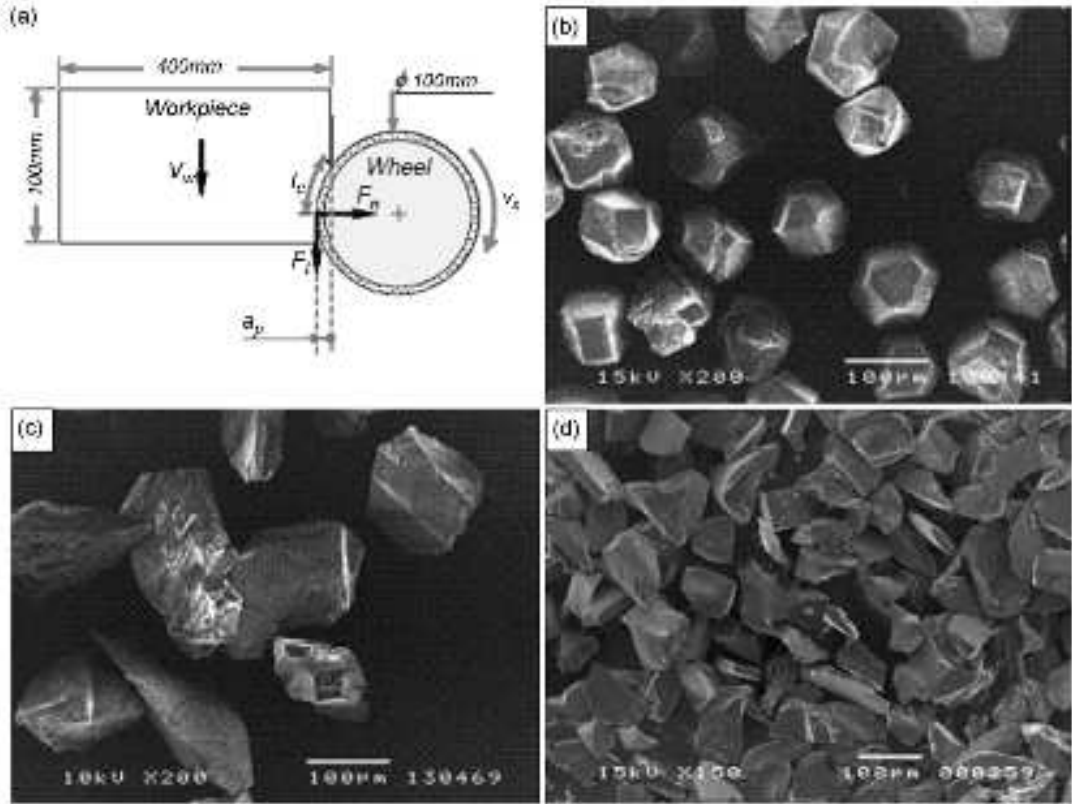

Fiz. 1. Illustrations of (a) grinding parameters and micrograpbs of (b) regulur diamond grains, (c) irregular diamond grains and (d) Sic grains.

Table 1

Characteristics of wheets used for experiments

\begin{tabular}{|c|c|c|c|c|}
\hline whed type & Specifications & Grain whe & Grain size $(\mu \mathrm{m})$ & Bond type \\
\hline Diansond-M & DC3 A6N525MB & Diamond & 46 & Copperalloy \\
\hline Diarsond- $R$ & D2K46R62.5876 & Diamond & 46 & Desin \\
\hline $\operatorname{sic} x$ & CARBOASBR625876 & Silicon cartbide & 46 & Mesin \\
\hline
\end{tabular}

The coordinate vector $\mathbf{r}(x, y)$ specifies two spatial coordinates. Thus, one useful property of the wavelet transform, when using continuous wavelets such as Mexican hat, is its ability to produce simultaneously a good local matching of the topographical signal features in the space and frequency domains. The scale " $\mathrm{a}$ " is therefore inversely proportional to all its characteristic frequencies. The methodology is to extract each scale by inverse wavelet trans. form, and to quantify the aritumetic mean value for each scale. The objective is to determine the spectrum of arithmetic mean (SMa) value from the scales of waviness to roughness (Zahouani et al., 2008).

In this study, surface topography of the glass edge was carried out by a three-dimensional white-light interferometer (WYKO NT 3300). The surface was sampled in $320 \times 1546$ points with a $3.88 \mathrm{\mu m}$ step scale in the $x$-direction and in the $y$-direction, which correspond to a surface of $1.24 \mathrm{~mm} \times 6 \mathrm{~mm}$

\section{Results and discussion}

\subsection{In/luence of nature of bond}

The influence of the nature of bond on surface edges finishing was studied. Two wheets with different bonds were used for experimental tests: a diamond grain/merallic-bonded wheet (diamond-M) and, a diamond grain/resin-bonded wheel (diamondR). The characteristics of the two wheel types are reported in Table 1 . The reason for enlightening the influence of bond stiffness, specific energy, force components, and surface finishing state were analyzed.

\subsubsection{Specific energy evoturion}

A fundamental parameter for characterizing the grinding pro cess is the specific energy, which is defined as the energy consumed per unit volume of material removed. The specific grinding energy defines the mechanisms of releasing of a glass volume fraction from the operated specimen. The evolution of specific energy with wheel velocities was studied for the two wheels considered. The plots of energy given in Fig. 2 were deduced from the power measured during grinding operation

As can be seen, for diamond-M wheel, the specific energy still remains relatively low $\left(\mathrm{s} / \mathrm{mm}^{-3}\right)$ up to $21 \mathrm{~ms}^{-1}$ after which it increases sharply to reach $15 \mathrm{~J} \mathrm{m^{3 }}$. From 22 to $30 \mathrm{~ms}^{-1}$, the specific energy remains almost constant. Bcyond the velocity of $30 \mathrm{~ms}^{-1}$, it falls by a factor of 3 to reach approximately $5 \mathrm{Jmm} \mathrm{mm}^{-3}$. This evolution shows three different energy regimes as explained in a previous work (Demirci et al., 2008). Using the diamond-R wheel specific energy remains relatively low for the velocities' range. It

Table 2

Grinding parameters used for the different wheels.

\begin{tabular}{|c|c|c|c|}
\hline Whed type & $s_{k}(\mathrm{~m} / \mathrm{k})$ & $N_{N}(\mathbf{m i n} m \mathrm{~m})$ & $a_{0}(m m)$ \\
\hline Diamond-M & $18,20,21,22,25,27,30,35,40$ & 1 & 0.1 \\
\hline Duenond - R & $18,20,22,25,27,30$ & $i$ & 0.1 \\
\hline $\operatorname{sic} \rightarrow R$ & $18,20,22,25,27,30$ & $i$ & a.1 \\
\hline
\end{tabular}




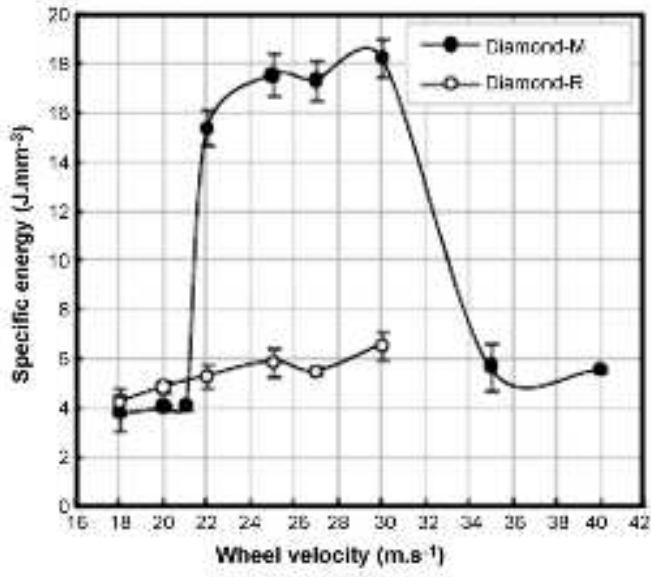

Fig 2. Specific energy vs, whed velocities.

increases slightly in linear manner between 4 and $7 / \mathrm{mm}^{-3}$. For this wheel, there is no transition zone, Beyond $30 \mathrm{~ms}^{-1}$, the resin of diamond $R$ wheel burns and this prevented in carrying out experiments at high velocity values.

\subsubsection{Grinding forces}

The evolution of the force with the wheel velocities has been studied for the two wheels used. The plots of both, the tangential and the normal components are given in Fig. 3. As observed for specific energy, the forces components recorded for diamond- $M$ wheel show three different zones. These different zones correspond to the three energy regimes explained above. The forces compo nents obtained using diamond $-\mathrm{M}$ increase quickly beyond $21 \mathrm{~ms}^{-1}$ and then, it starts to fall slightly until a velocity of $30 \mathrm{~ms}^{-1}$. After that, it drops to reach values close to those obtained in regime where velocity is relatively low. However, the normal and tangential forces seem to stagnate at 41 and $8 \mathrm{~N}$, respectively, when the resin-bonded wheel is used.

The fact that there is no transition observed in specific energy and force components in the data obtained with diamond- $R$ wheel implies that there is only one material removal regime when grinding the glass. In order to support this finding SEM observations and multi-scale analysis were performed forcharacterizing the materia removal mechanisms, Microscopic inspections were used to exam ine the damage on the ground surface. However, the different scales of the surface signature, be, roughness, waviness corresponding to streak generation, and form defect, were investigated by using the second technique of analysis.

3.1. Material removal mechanisms: damage

Ground surfaces obtained with both the diamond-R and the diamond-M wheels were characterized for the different regimes, Only one velocity was considered per regime. SEM micrographs corresponding to each regime are presented in Fig. 4. Micrographs obtained using diamond-R were compared to those reported in the previouss work (Demirci et al., 2008). In comparison, focus is essentially put on damage generated by material removal mechanisms.

Firstly, it can be seen that the surfaces finished by diamond- $\mathbb{R}$ wheel exhibit similar aspects and this implies that the mecha nism of material removal is insensitive to the velocity. From the micrographs of Fig. 4a-c, it appears that there exists a plough ing phenomenon for the three cases caused by a double action of wheel motion. A first action, dealing with brittle phase, occurs as
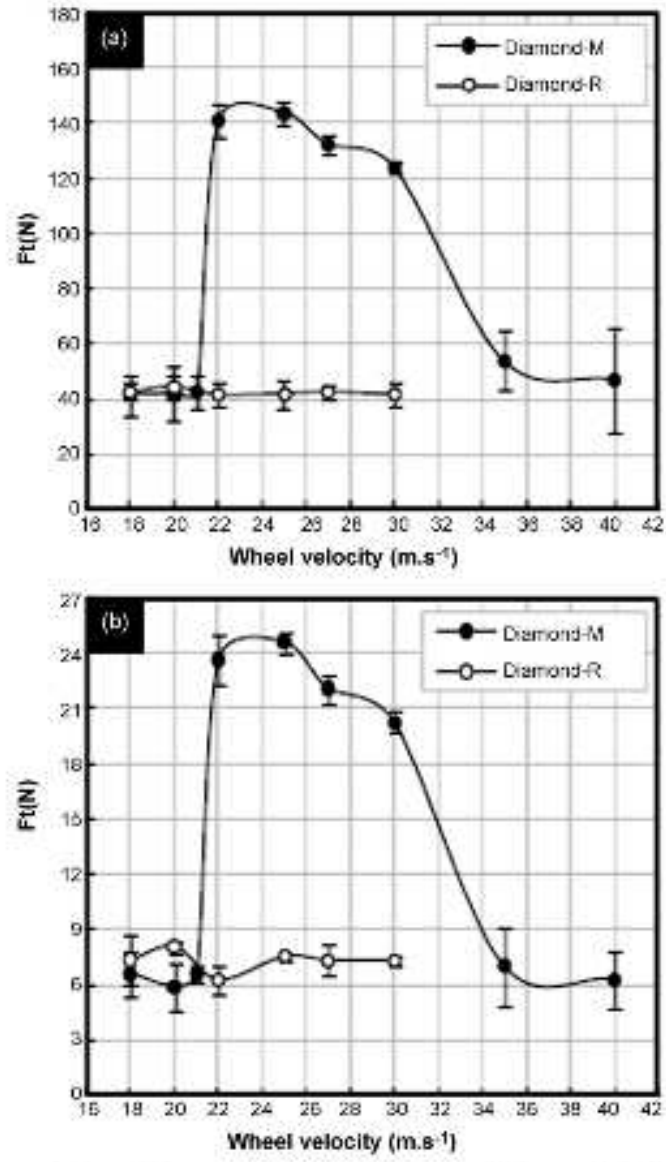

Fig. 3. (a) Normal force vs. wherl velocity and (b) Tangental force vs, wheel veloc ny.

soon as the wheed comes into contact with the glass surface. At the first stage, multiple microcracks would initiate rapidly from the sharp zones of wheel grains, which is typical to abrasion operations (Swain, 1979). A second action taking place once cracks initiated at the contact of wheel grains, consists in pushing over the material in such a manner to disappear the sharp peaks at ground surface. It results in a combination of a brittle mechanisms and a ductile mechanism, which is known as partial ductile regime.

As can be seen in Fig. 4d and e (partial ductile regime) (fragmentation regime), the ground surfaces obtained with the metallic-bonded wheel are quite different from those obtained with resin bonded wheel at identical velocities, However, Fig, $4 f$ shows an aspect much more similar to the aspect of ground surfaces using diamond-R wheel. Thus, it can be underlined that material removed by resin-bonded wheel corresponds to a partial ductile regime.

The presence of unique regime in resin-bonded grinding may be explained by tow mechanisms, In one hand, the wear mechanism acts much more markedly on resin bond than on metallic bond and thus leading to different kinetics of regeneration of active grains. This means that during the test time, grains in contact with job surface have a shape very close to that of new grains. In another hano, 

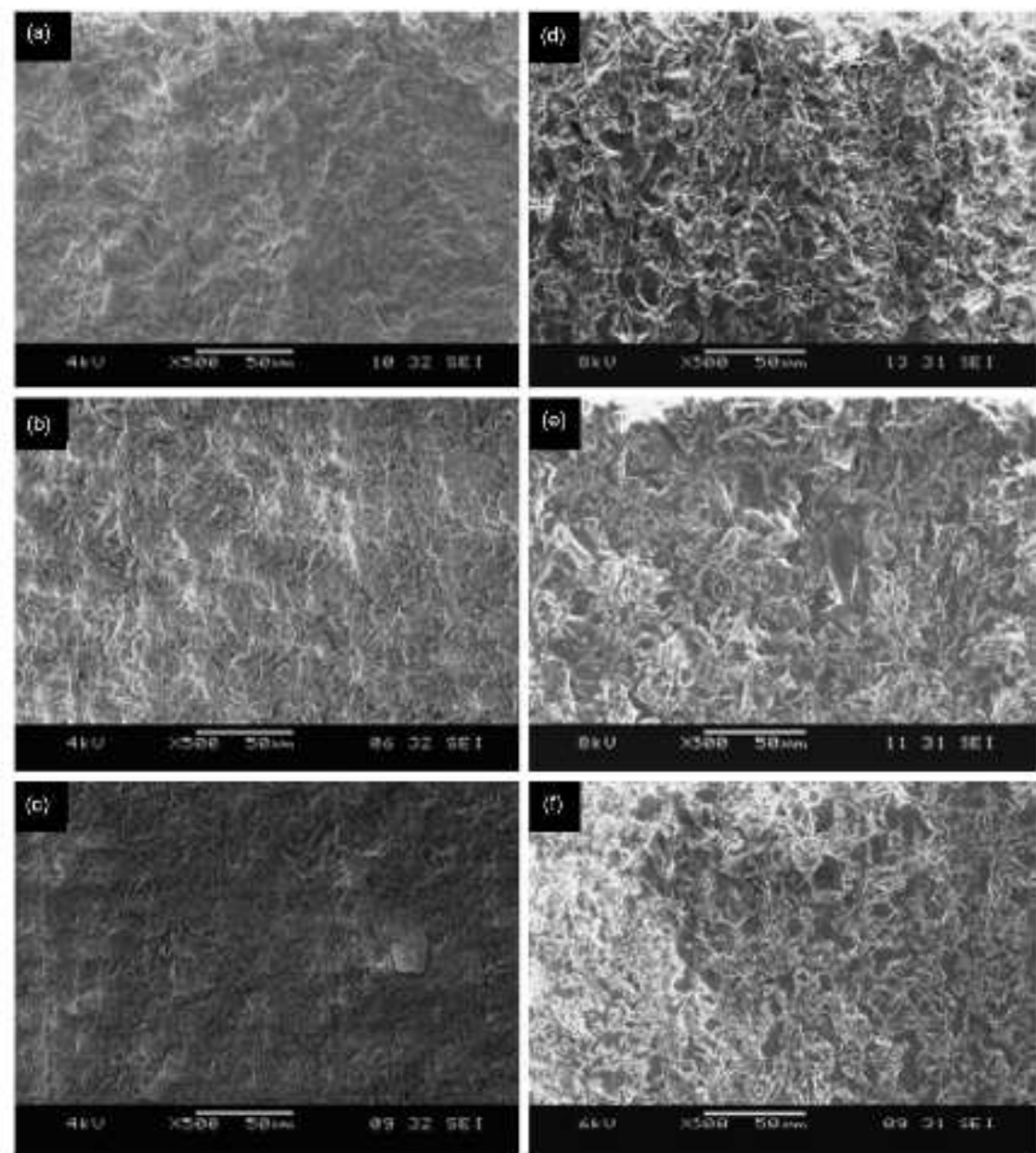

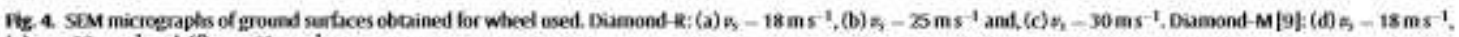
(e) is $-25 \mathrm{~ms}^{-1}$ and, $(1) \mathrm{s}_{3}-40 \mathrm{~ms} \mathrm{~s}^{-1}$

the temperature growth simultaneously acts on the wear mecha nisms in such a manner so as to enhance the regeneration of grains' layer by softening the resin through heat effects. This leads to a high wear rate through mechanical wear of the bond around the grains.

\subsubsection{Surface finish characterization}

Fig. 5 shows the SMa spectrum on various scales for different velocities and the two wheels used Three different zones corresponding to the different features scales were distinguished.

The right zone is associated to high frequencies and corresponds to roughness scale. The central zone is related to the wavinessscale, which is defined here as the amplitude of streaks. Finally, the left zone results in the form defects induced by the grinding wheet.

For the ground surfaces obtained using resin-bonded, the waviness zone does not exhibit peak, thus proving the absence of streaks. as was observed in SEM micrographs. Nevertheless, high peaks in the waviness zone were observed in ground surfaces obtained using metallic-bonded wheel. This corresponds to streaks localized on a scale of $0.85 \mathrm{~mm}$. The absence of streaks does not mean that the damage regime is only brittle; however, it indicates that there are no ploughing mechanisms. The presence of displaced mate. rial, as described in previous section, justifies the partial ductile mode. These findings are well consistent with the observations of Venkatesh et al. (2005)

For the diamond $R$, the roughness measured for both the velocities of 18 and $30 \mathrm{~ms}^{-1}$ is approximately the same.SMa still remains relatively constant about a mean value of $0.15 \mu \mathrm{m}$. This value of $S M a$ coincides closely with the one obtained using diamond-M at $30 \mathrm{~ms}^{-1}$. However, at 18 and $40 \mathrm{~ms}^{-1}$, the $S M a$ value measured at diamond-M ground surfaces varies between 0.15 and $0.3 \mu \mathrm{m}$. Thus, SMa discrepancy is shown to be lower on ground surface using diamond-R wheel, which implies that the roughness obtained on glass surface with diamond-R wheel is better than the one acquired using diamond-M. The absence of peaks observed on SMa of diamond-R ground surface lies to the absence of form defects.

\subsection{Influence of grains}

The influence of grain's nature on grinding of glass was investigated using resin-bondled wheel. Results obtained during grinding 


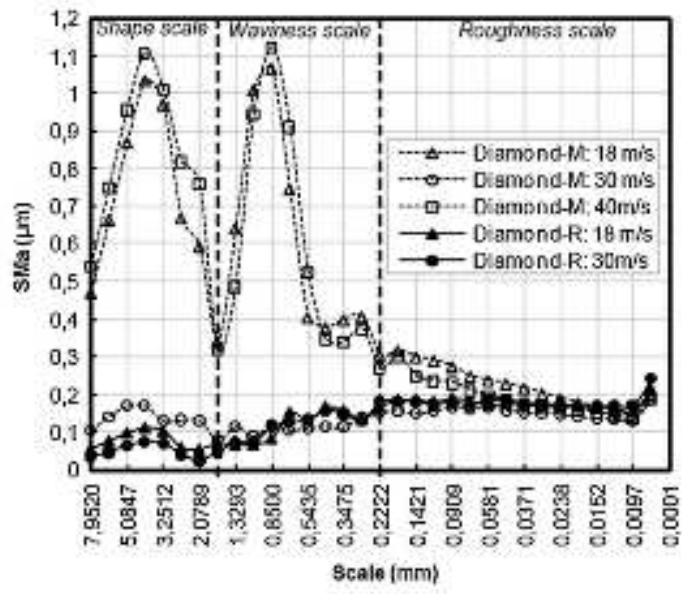

Fig 5. cvolution of the sMa spectrum vs. scale.

with diamond grains were confronted to those obtained from the grinding of the same glass with silicon carbide grains, In particular. material removal was discussed through damage inspections and scales were accordingly detailed by SMa analysis.

\subsubsection{Specific energy evolution}

The specific energy was evaluated from the power mea sured during the experiments carried out using SiC-R wheel and diamond- $R$ wheel. The evolution of the energy with the wheel velocity is given in Fig. 6. As illustrated, the specific energy in the two cases remains nearly constant when the wheel velocity increases. However, the energy obtained with SiC grains whee $\left(\sim 24 J \mathrm{~mm}^{-3}\right)$ is approximately four times higher than the energy obtained with diamond grains wheel $\left(\sim 6 \mathrm{~J} \mathrm{~mm}^{-3}\right)$. The wide discrepancy between the two curves is fundamentally explained by a difference in terms of material removal mechanisms. The stability observed in energy should prove, one more time, that there exists only one regime of removal material.

\subsection{Grinding forces}

The evolution of the force with the wheel velocity was studied for the two considered grains types. The plots of both, the tangential and the normal components given in Fig. 7 , are relatively constant

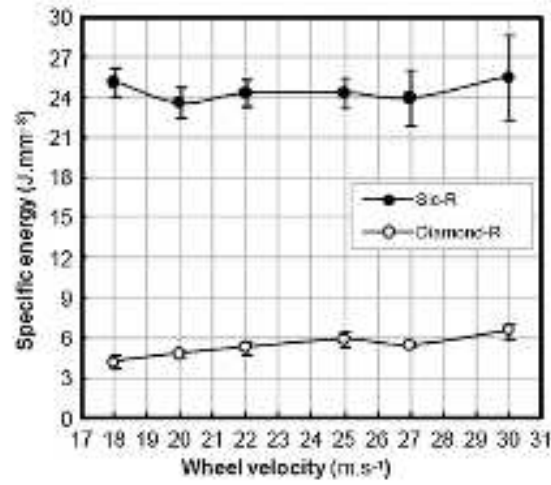

Aig. 6. specific energy vs, whed velocity
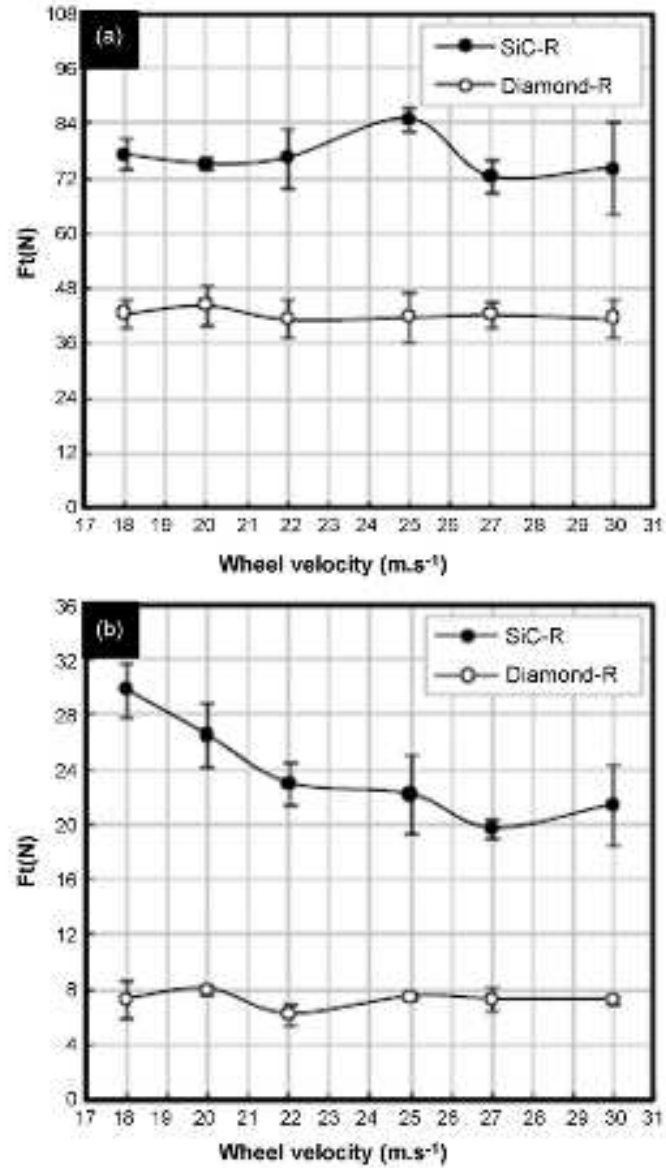

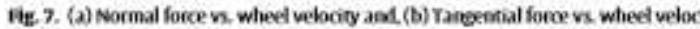
ity.

when the wheel velocity increases. Besides, a marked discrepancy between the two curves was observed. Normal force recorded for $\mathrm{SiC}$ grains wheel reaches $80 \mathrm{~N}$, while the one recorded for diamond grains wheel exceeds slightly the half of that value. Although fluctuations appeared higher for SiC grain's tool, their level did not exceed $10 x$

Similarly, the tangential force engendered by diamond grains fool does not exhibit marked variation with the velocity and remains relatively constant as seen for nomal components. On contrary, $\mathrm{SiC}$ grains wheel seems to act in such a manner to decrease the tangential force by about 1.4 times lower when the velocity increases by a factor of about 1.66 . Therefore, the force generated by the $\mathrm{SiC}$ wheel is higher than the one generated by the diamond one whatever the velocity value. The maximum ratio between the two curves of tangential force obtained reaches approximately 4.

These results are in good concordance with those of Huerta (1974), who found that the grinding forces obtained with SiC grains' tools are approximately one order of magnitude higher than those obtained using diamond grains' tools.

The deviation in force level obtained by SiC grains' tool and diamond grains' tool allows to conslude that the nature of regime is eventually different. As the bond is the same, only the nature of 

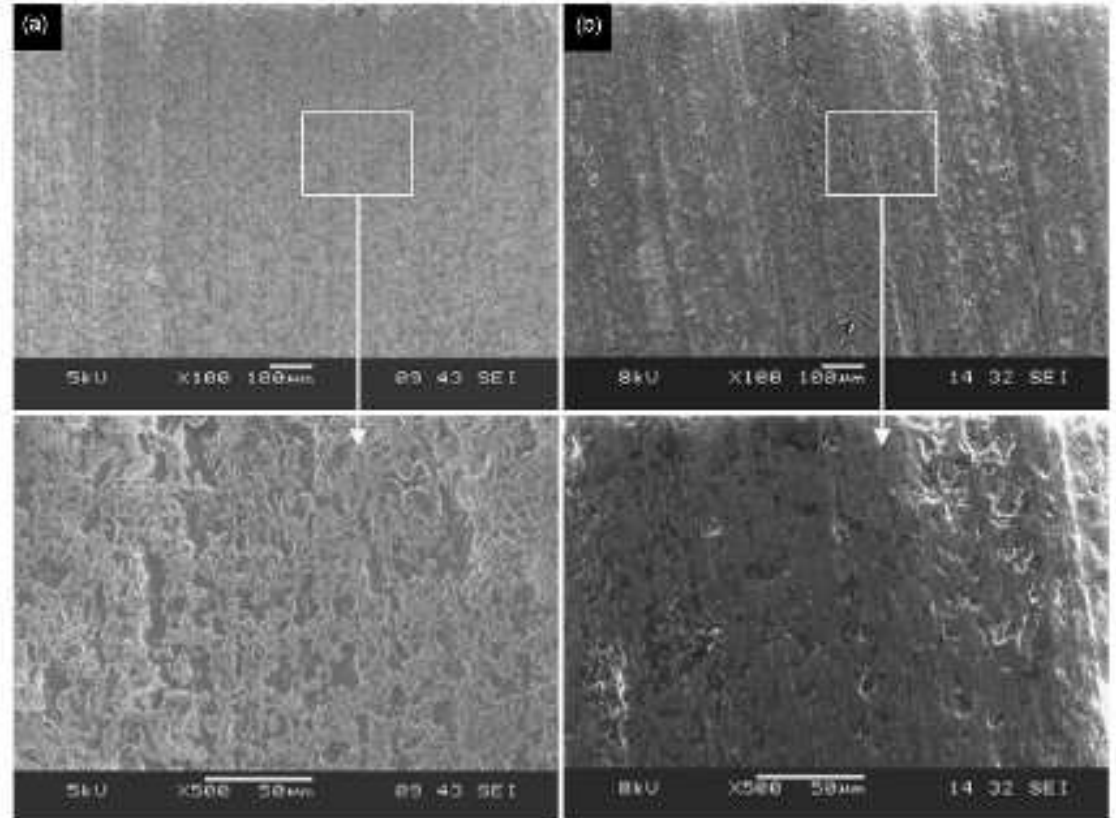

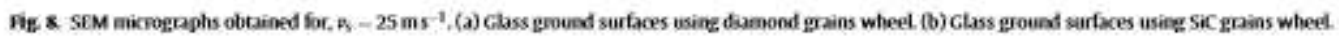

grains can explain an eventual difference in the regime nature, The fracture toughness of silicon carbide is lower when compared to that of diamonds, making it very susceptible of cracking and therefore leading to the formation of sharp grains. These sharp grains allow the flow unlike diamonds grains, which tend to become blunt and contribute to the appearance of cracks (Chiang et al., 1982). This could be revealed through the analysis of surfaces finish.

\subsubsection{Material removal mechanisms: damage}

SEM micrographs of ground surfaces obtained by means of dia mond grains' tool and silicon carbide grains were investigated at least for $25 \mathrm{~ms}^{-1}$ in order to characterize the material removal mechanisms. Fig. 8 a shows the surface aspect following grinding using diamond grains wheel.

In spite of the appearing of facets as a consequence of brittle fracture, the micrograph exhibits traces that prove the existence of an eventual material flow. This should result in the partial ductile regime with displaced material as previously discussed.

The surface aspect obtained esing silicon carbide grains tool, given in Fig. $8 \mathrm{~b}$, seems to be quite different from the diamond grains' ground surface. The SiC grains' tool leads to more marked streaks, which prove that material was removed according to a ductile mechanism. Besides, the absence of facets indicates that brittle fracture is unlikely. Thus, material removed by means of silicon carbide tool was reflected by a ductile regime characterized by an extensive plastic flow and sparsely brittle damage; the level of britthe damage is reduced in SiC ground samples. These interpretations were supported by the nature of surface aspect, which is shown in the enlarged view of Fig. $8 \mathrm{~b}$

\subsubsection{Surface finish charocterizorion}

Fig, 9 shows the SMa spectrum built following the grinding of surfaces using the two resin-bonded wheels. In particular, surfaces obtained at 18 and $30 \mathrm{~ms}^{-1}$, were examined.
At roughness scale (right zone), the SMa plots seem to be con scant with a mean value of $0.5 \mathrm{um}$ for the SiC grains wheel, and about $0.18 \mu \mathrm{m}$ for the diamond grains wheet. The surfaces obtained with silicon carbide grains' tool have a slightly better roughness than those obtained with diamond grains' tool.

In waviness scale, the surfaces obtained with $\mathrm{SaC}$ grains wheel exhibit peaks with marked intensity, whereas one of the peaks of ground surfaces using diamond grains wheel is observed much lower. The presence of the peak justifies the material flow (ploughing) due to a ductile regime. On contrary, a low peak value as seen with diamond grains should prove the presence of low ploughing amplitude results in a partial ductile regime.

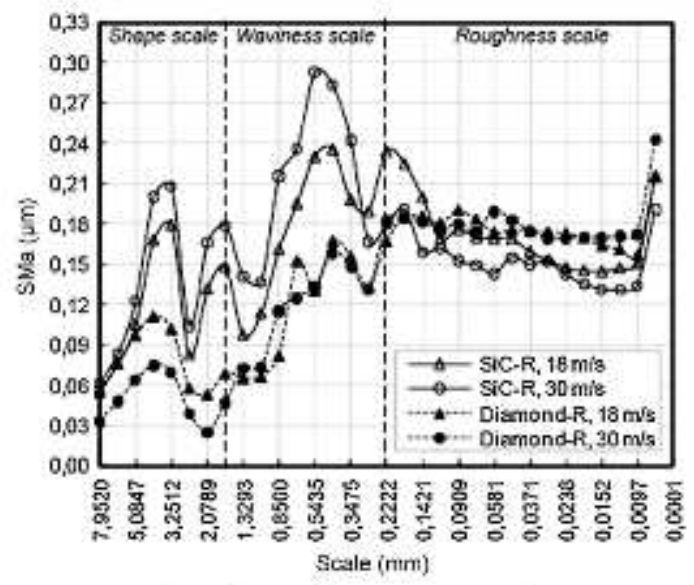

7ig. 3. Evolution of the SMs spectrum ws scale. 
It was also interesting to point out that the form defects are more pronounced when surfaces are achieved with silicon carbide grains' tool (peak in shape scale) than those ground with diamond grains' tool.

Analysis of specific energy confirms the difference in regimes, The energy spent when grinding with silicon carbide grains' tool is higher than the one generated during grinding by diamond grains wheels. An extensive flow should require a large energy (Huerta 1974). As observed here, the roughness of glass surfaces obtainer with silicon carbide grains is better than that obtained with diamond grains. This is in good agreement with literature findings that (Brown et aL, 1989) indicated that the fragile regime is generally characterized by a higher roughness unlike to ductile regime that results in lower roughness.

\section{Conclusions}

This work attempts to study the influence of bonds and grains type of abrasive tools during glass grinding. For these reasons, three different wheels are used. The following concluding remarks can be underlined:

- Firstly, resin bond and metallic bond were used in diamond grains' tools to investigate the variation of the surface finish aspect with the nature of the bond. As reported in a previous work, metallic bond encompassing diamond grains' tool, which has lead to three various regimes of material removal, can be easily distinguished through the variation of grinding energy when velocity increases, On contrary, a single regime associatex with partial ductile material removal mechanisms was identified when glass surface was ground using diamond grains' tool consisting of a resin bond.

- Secondly, the influence of the abrasive grains' nature is investi gated while only one bond type, i.e. resin bond, is considered, Surface achieved by diamond grains' tool and silicon carbide too are compared with another. The analysis of ground specimens showed that there exists a difference in material removal mechanisms between the silicon carbide grains' finish surface and the diamond grains' finish surface, Ductile regime obtained with $\mathrm{SiC}$ grains' tool seems to result in a ductile flow while diamond grains' tool seems to result in a partial ductile flow combined with displaced material.

\section{Acknowledgement}

The authors would like to gratefully acknowledge $S$. Crequy for this dedication during this work.

\section{References}

Belkhir, N., Bouzid, D., Herold, $v_{2}, 2007$. Correlation between the surface quality and the abrasive grains wear in optical glass Lipping Tribol. Int. 40,498

Bowden, F.P. Hughes, T.P., 1937. Physical properties of surfaces. IV. Polishing, sur face flow and the formation of the Beilby layer. Proc. R. Soc. Lond. A160, 575-

Bowden, F.P. Scott, H.G, 1958. The polishing glass. Proc R. Soc Lond. A248, 368-378

$24,400-413$.

Brown Ny. Fuchs, B. . Hed, P.P. Stowers, LF. 1989. Response of isotropic brittle tional Frequency Control symesposium. Procedings of the Annual IEEE Interna 616.

Chiane SS, Marshall, DR, Evang, AG. 1982 . The response of the solids to elas ticjplastic indentation. . Appl. Plys. 53, 298-311

Deminci L. Merghtani S. El Mansori, M. 2008 . On the removal shaping of the glass edges: forces analyses, surface topography and damuge mechanism. Tribol. Let! 30. $141-150$.

Desmars, Y, Margerand, S, 1994 Rappel sur ke faconnage du verte. in: Rappon technique. Centre de D/voloppecment industrict Saint-Cobain Class ThourotteFelden J.H, Rubenstein, C., 1969. The grinding of glass by a fixed abrasive. Glass Technol. 10, 73-83.

Hoerta, M., 1974. Grinding of glass and effects on surface structure and fracture strength. Ph.D, The University of Texas, Austin.

Lee, S.H. Z.houni, H., Caterini, R, M.thia, T.G., 1998 . Morphological characteriza tion of engineered surfaces by wawelet transform. Int $\mathrm{f}$ - Mach. Tools Manufact 38, 5\$1-589.

Lua, SY, Tsai, Y.Y, Chena, CH, 2006. Stadies on cut-off grinding of EKT optical glass using thin diamond wheels. I Matec. Process. Tech. 173, 321 329.

Mirloc, H., 1972. Texture of ground glass surfaces, Ind. Diamond Rev. 1, 61 .

Malkin, S, 1989. Grinding Technology: Theory and Applications of Machining with Mbrasives, first ed. Socicty of Manufacturing Engineers, Dearbom, Michipan.

Sum, X, Stephenson, DJ. Ohnish, O, Baldwin, A, 2006. An investigation into paralle and cross grinding of BK7 glass. Precis. Eng 30, 145-153.

. 1365, $575-597$.

Takalushi, T., Funkenbusch, P.D, 2000 Micromectunics of dianond composite tools during grinding of glass. Mater. Sci. Eng $1285,69-79$.

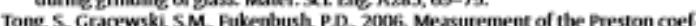
ficient of resin and bronzer bond tooks for deterministic microgrinding of obsuss Precis. Eng, 30, 112-115.

Vaidyanathan, S. Finnie, I, 1972 In: Shaw, MC. (Fd), New Dewelopments in Crinding - in Grinding of Brittle Solds, Pittsburgh, PA, pp 813 831.

Venk.tesh, V.C, Izman, S, Vichure, P.S, Mon, T.I_Muriwan, S, 2000 . The novel bond. kess wheel, spherical glass dips and a new method of aspheric generation. Mater. Process. Tech. 167, 184-190

Zahouani, H., Lee, S.H., Varpiolu, R. Rousseau, J. 2001. Characterization of surface topograply by continoous wavelet transforms. Act Plys. Superficierum IV, $1-23$.

Zalousani, H., Mezghani, S., Vargiolu, R., Dursape, M, 2008 Identification of manufacturing segnature by $2 \mathrm{D}$ wavelet decomposition. Wear 254, 480-

Zhoeg Z, 2003. Ductile or partial ductile mode machining of brittle materials. Int. J. Adv. Manuf. Techool. 21,579-585. 